\title{
Subway Station Real-time Indoor Positioning System for Cell Phones
}

\section{Chengqi Ma, David R. Selviah}

University College London, UCL, London, United Kingdom WC1E 7JE

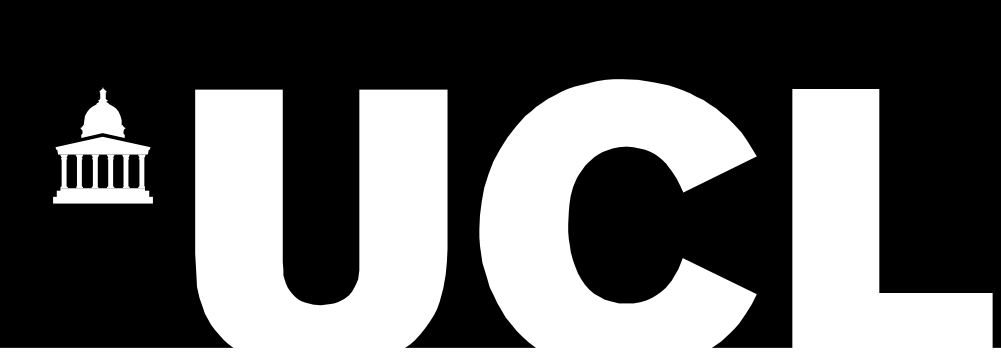

\section{Introduction}

- As wireless local area network, WLAN, access point (AP) are becoming very common wireless communication infrastructures in indoor environments, Wi-Fi signal based Indoor Positioning Systems (IPS) have been widely developed in recent years.

- This project combines both Wi-Fi fingerprinting and Pedestrian Dead-reckoning (PDR) technologies to introduce a real-time indoor navigation system for large complex three-dimensional indoor environments including a novel calibration method with associated matching algorithms.

- Detailed experiments were conducted in two subway stations with complicated structure under normal operating conditions in which trains regularly arrived and departed and groups of people walked to and from the trains.

\section{Offline phase - Calibration and mapping}

- Database establishment - Data collected by walking.

- Unique RSS histogram distribution due to walking calibration method and environmental effects.

- Direction information coefficient.

Probability of occurrence.
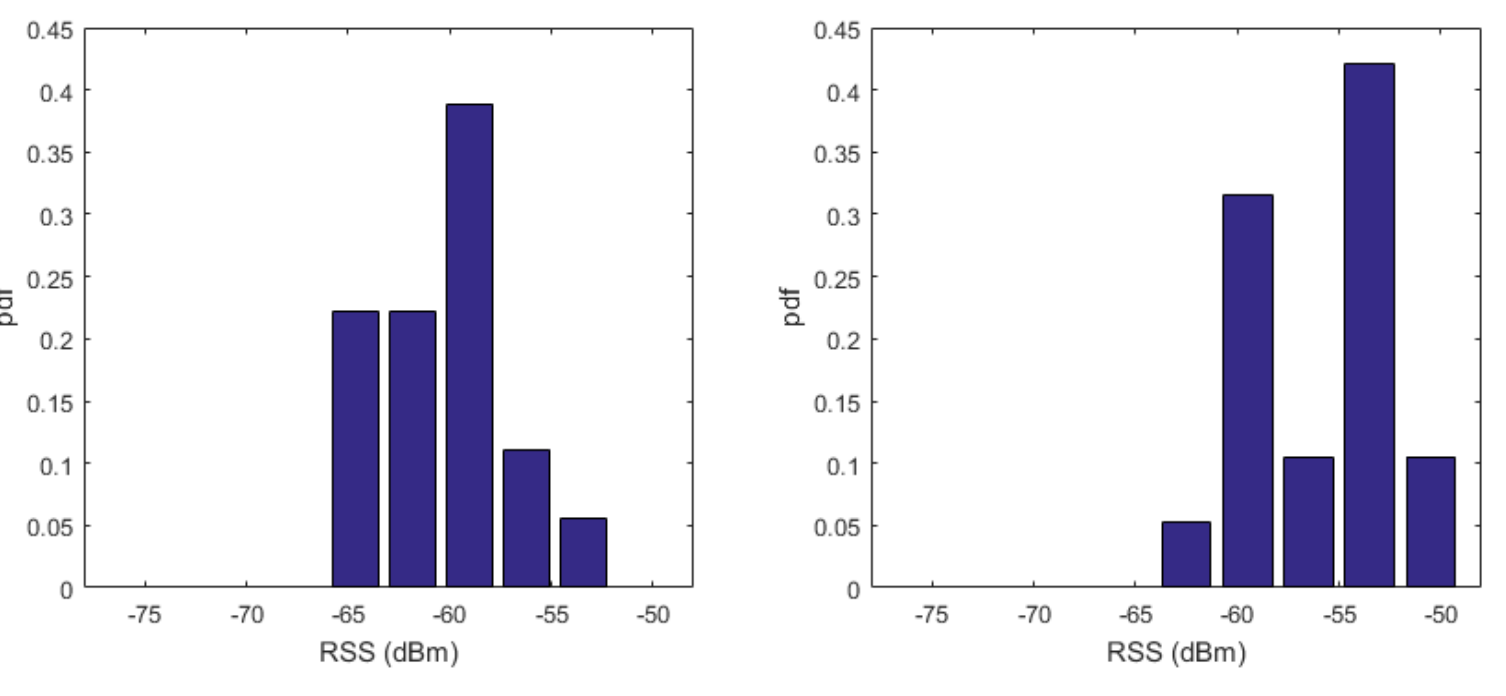

- Pedestrian Dead-reckoning (PDR) mapping support - PDR method to record and simplify reference point position.

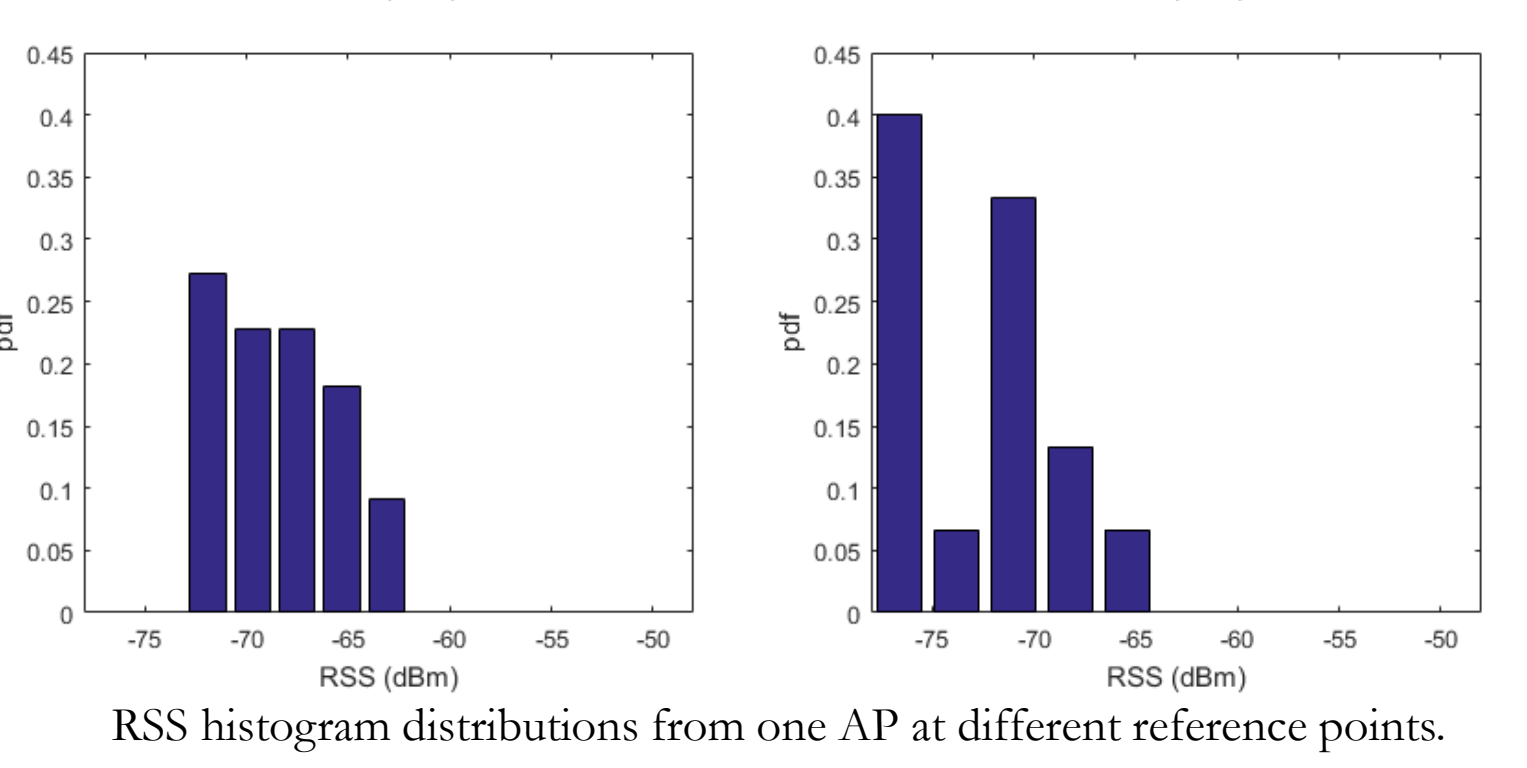

\section{Problems and Challenges}

- Cost in calibration

Data collecting in large and complex

environments can be extremely labourintensive and time-consuming by fixed reference point.

- Body block effect

A person's body have a large effect on signals receiving from all the APs behind the person. The RSS can be very different when the phone holder is walking in different directions.

- Environmental variation effect

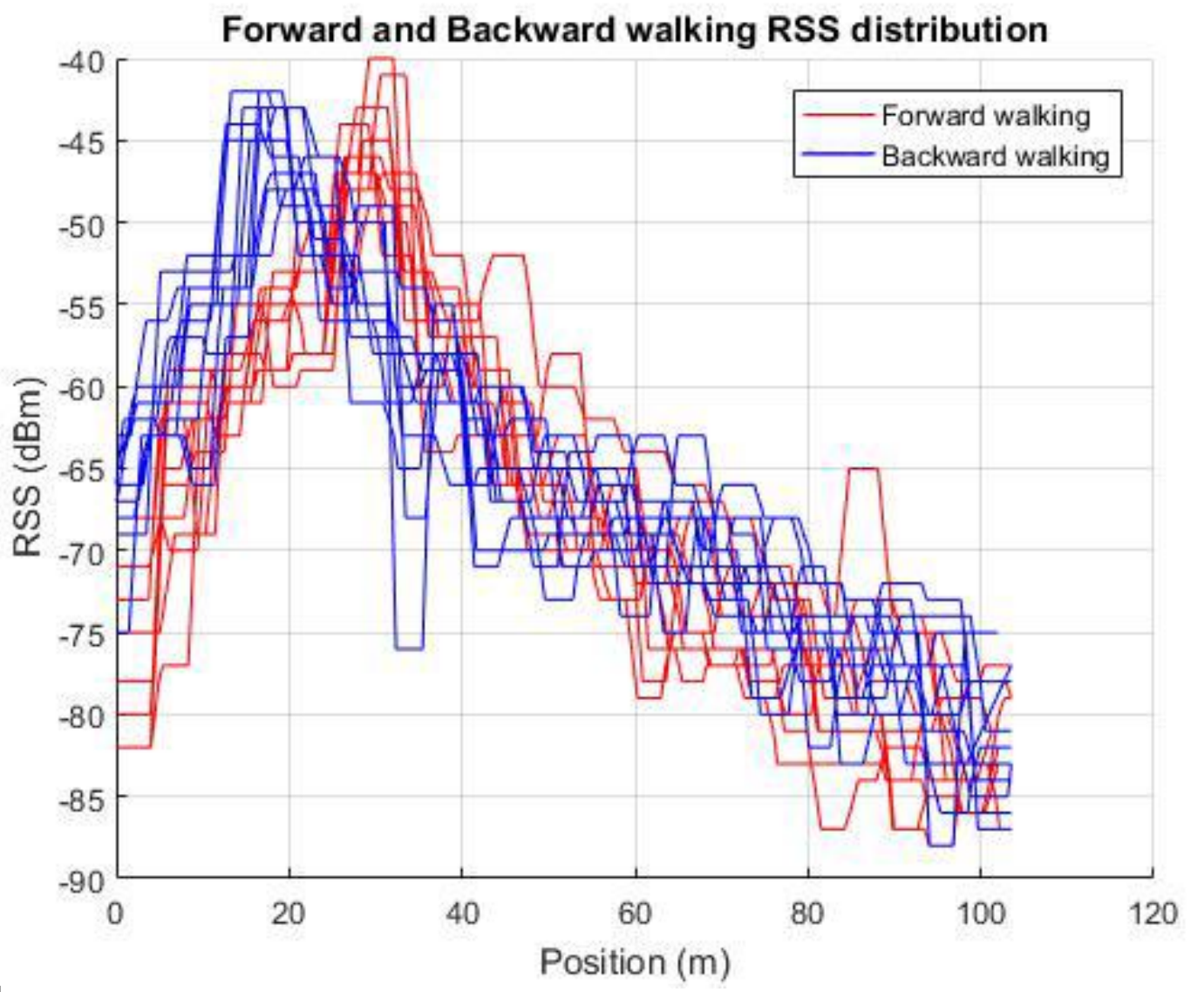

The Wi-Fi signal strength can be significantly influenced by periodically arriving and departing metallic trains as well as groups of people getting on and off the trains and walking around the station itself.

\section{Online phase - Matching and Filtering}

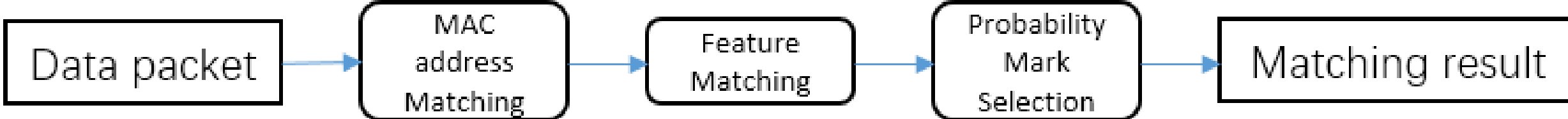

- Matching processing

- Quick selection by pre-classified MAC address groups.

Matching with recorded unique RSS distribution.

Final selection by calculated Probability Mark

$$
\text { Mark }=\frac{\sum_{i=0}^{n} \operatorname{Pr} i \cdot R i \cdot D}{n}
$$

Where Pri is the feature matched probability; $\boldsymbol{R} \boldsymbol{i}$ is the probability of occurrence $D$ is the direction information coefficient.

\section{- Discrete Kalman Filter}

Trajectory smoothing.

Missing point prediction.

\section{System Performance}
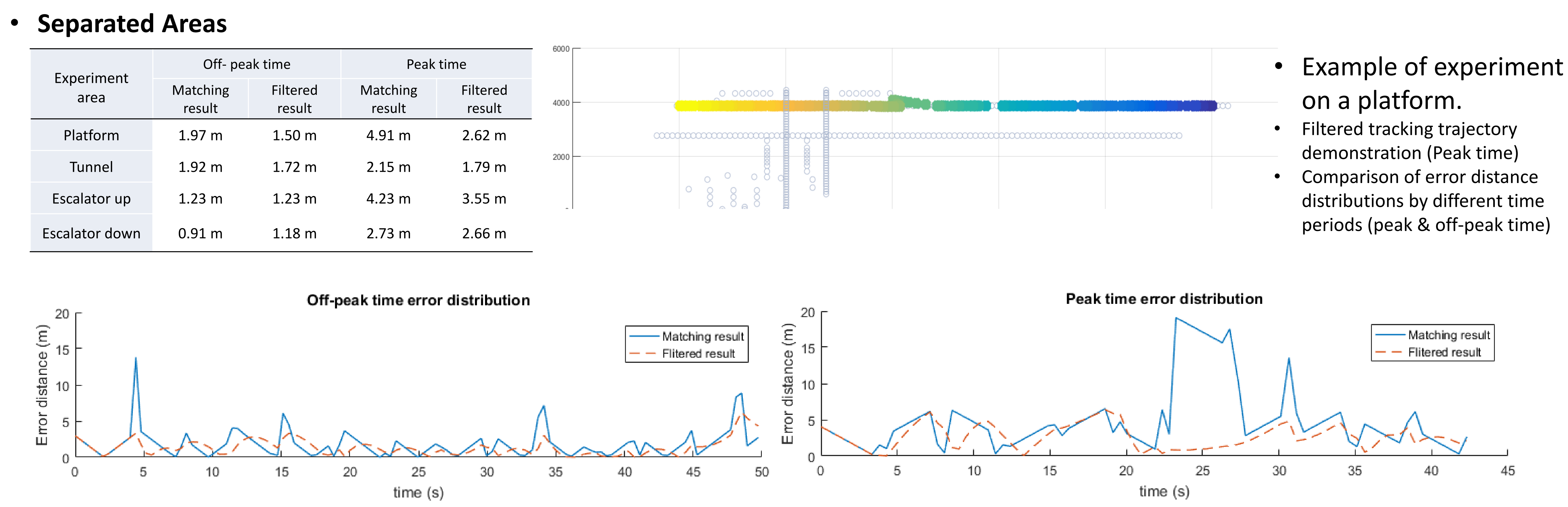

\begin{tabular}{c|c|c|c|c} 
- Overall & \multicolumn{3}{c}{ Off- peak time } & \multicolumn{2}{c}{ Peak time } \\
\hline $\begin{array}{c}\text { System } \\
\text { performance }\end{array}$ & $\begin{array}{c}\text { Matching } \\
\text { result }\end{array}$ & $\begin{array}{c}\text { Filtered } \\
\text { result }\end{array}$ & $\begin{array}{c}\text { Matching } \\
\text { result }\end{array}$ & $\begin{array}{c}\text { Filtered } \\
\text { result }\end{array}$ \\
\hline $\begin{array}{c}\text { Overall } \\
\text { average error } \\
\text { distance }\end{array}$ & $2.37 \mathrm{~m}$ & $\mathbf{1 . 7 1} \mathrm{m}$ & $3.42 \mathrm{~m}$ & $\mathbf{2 . 9 0 ~ m}$ \\
$\begin{array}{c}80 \% \text { CDF } \\
\text { error distance }\end{array}$ & $<2.91 \mathrm{~m}$ & $<\mathbf{2 . 5 4} \mathrm{m}$ & $<4.77 \mathrm{~m}$ & $<\mathbf{4 . 2 ~ m}$ \\
\hline
\end{tabular}

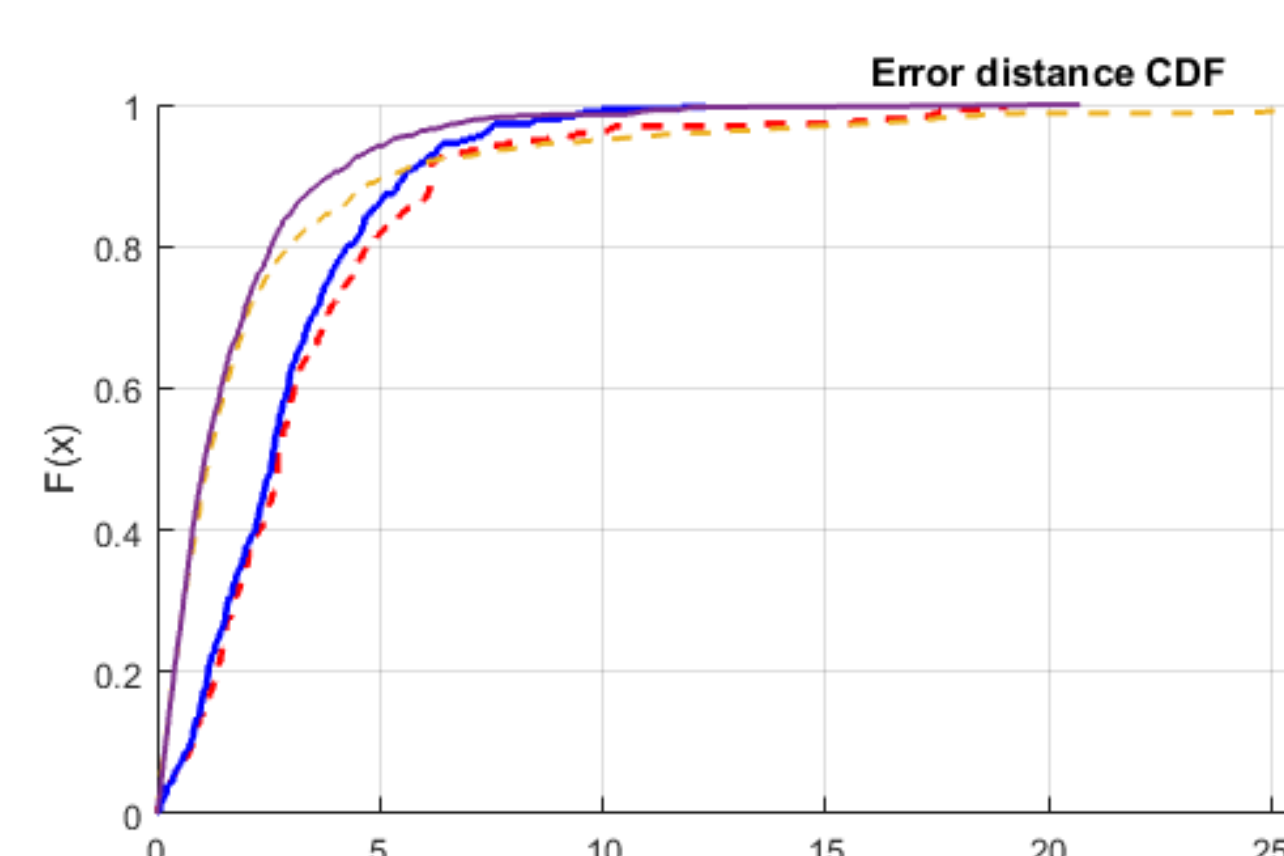

- Experiment of tracking real passenger can achieve average tracking accuracy, 1.7 metres during off-peak times and 2.9 metres during peak passenger traffic times, which fully meets the initial aim of this research to record the walking tracks of the passengers. 